RU Эдгар По и Германия: о некоторых аспектах взаимовлияния

Жулёва Л. П.

Аннотация. Цель исследования - выявить аспекты взаимодействия Эдгара По и немецкого мира. Научная новизна заключается во введении в научный оборот ранее не переведенных зарубежных источников по предлагаемой теме, что позволило комплексно представить общий обзор влияния немецкой культуры и немецкого языка на творчество Э. По, а также осветить рецепцию прозы американского писателя в Германии. Полученные результаты показали, что, несмотря на отрицание самим писателем влияния германизма на его произведения, они оказались близки немецким авторам, что в дальнейшем отразилось и во взаимодействии двух литератур.

\title{
EN Edgar Allan Poe and Germany: On Some Aspects of Their Mutual Influence
}

\author{
Zhuliova L. P.
}

\begin{abstract}
The purpose of the study is to identify aspects of interaction between Edgar Allan Poe and the German world. Scientific novelty of the research lies in introducing previously untranslated foreign sources on the proposed topic into scientific use, which made it possible to give a comprehensive overview of the German culture and language influence on E. A. Poe's creative work, as well as to shed light on reception of the American writer's prose in Germany. The research findings have shown that despite the fact that the writer himself denied Germanism influence on his works, they resonated with the German authors, which was later reflected in interaction of the two literatures.
\end{abstract}

\section{Введение}

Актуальность изучения взаимодействия творчества Э. А. По и немецкой культуры и языка соотносится с тенденцией изучения диалога культур и находится в русле соответствующих компаративных исследований, посвященных проблемам культурного трансфера, переводоведения и рецептивной эстетики. В рамках нашей статьи были поставлены следующие задачи:

1) выявить и описать основные элементы прозы Э. По, наиболее ярко демонстрирующие влияние немецкой культуры на его творчество;

2) определить функции вкраплений из немецкого языка в прозе Э. По;

3) проанализировать общую рецепцию его творчества в Германии.

Методами исследования стали: фронтальный анализ оригиналов ранней прозы Э. По, сфокусированный на выявлении элементов немецкой готики; сравнительно-сопоставительный анализ разных изданий новелл для определения роли немецких вкраплений; целостный анализ зарубежных источников, проведенный с целью систематизации и описания основных тенденций в восприятии творчества американского писателя в Германии.

Теоретическую базу исследования составляют литературоведческие работы, посвященные различным аспектам творчества По, а также его рецепции за рубежом. Общая характеристика творчества американского писателя и, в частности, поэтики многоязычия в его новеллах представлена в основополагающем труде Ю. В. Ковалева [4]. Элементы готики и характер их присутствия в прозе По рассматривались Э. Ф. Осиповой [6]. Роль и функции иноязычных вкраплений в коротких рассказах По подробно освещены в статье Э. Н. Абсалямовой [1]. Для изучения рецепции прозы По в Германии были проанализированы труды зарубежных исследователей, собранные автором данной статьи в рамках научной стажировки в университете г. Мангейм и ранее не переведенные на русский язык. Информация о некоторых важных аспектах жизни и творчества По содержится в трудах В. Биттнера [9], Л. Вайсберг [23], Д. Томаса и Д. К. Джексона [21]. О поэтике и генезисе страха в творчестве американского писателя писал Т. Колмер [10]. Работа Б. Фишера посвящена разбору одной из самых ярких «готических» новелл По - «Метценгерштейн» [11]. Итоги различных исследований зарубежной рецепции По представлены в сборнике Л. Д. Вайнса [22], в частности, о рецепции в Германии - в статье 
Р. Форклаца [12]. Интермедиальное усвоение новелл писателя подробно освещено в работах Дж. Майерса [13], Р. Б. Палмера [14], С. Пиплса [15], Д. Г. Смита [20].

Практическая значимость работы: материалы и результаты исследования могут быть использованы в подготовке и научно-методическом сопровождении практических курсов, сфокусированных на вопросах сравнительного литературоведения, художественного перевода, рецепции иноязычных художественных произведений в культуре принимающего языка. Обозначенные в работе направления исследования могут получить разработку в спецсеминарах соответствующей направленности.

\section{Влияние Германии на прозу Э. А. По}

О возможном влиянии Германии на творчество Эдгара По критики заговорили еще при публикации его первого сборника новелл «Гротески и арабески», который вызвал большой резонанс, несмотря на незначительный коммерческий успех. А. Танасейчук пишет о противоречивости полученных образов: с одной стороны, с воодушевлением была отмечена «причудливая фантазия автора», с другой стороны, некоторым критикам казалось явным и неприкрытым следование «германской» традиции в прозе и связанным с ней стереотипам [8, с. 70]. Сам По словно предчувствовал такой исход и в своем предисловии к сборнику отрицал «германизм» своих новелл.

Тем не менее, можно выявить два аспекта в характере проявления немецкого культурного фона в прозе По. Во-первых, в некоторых новеллах присутствуют элементы, навеянные образами немецкой литературы. Во-вторых, непосредственным компонентом сюжета ряда рассказов является активное использование собственно немецкого языка для создания особого эффекта правдоподобия - важнейшего компонента любой успешной новеллы, согласно мнению самого автора, изложенному в эссе «Философия творчества» [18].

Рассмотрим наиболее яркие готические элементы в новеллах По. «Метценгерштейн» (“Metzengerstein”) его первый опубликованный рассказ, напечатанный в филадельфийском журнале “Saturday Courier” в 1832 году. При жизни писателя данная новелла переиздавалась ещё дважды, в изменённых редакциях, в 1836 г. и в 1839 г. - с подзаголовком «История в немецком стиле» (“А Tale in Imitation of the German”) [16]. На примере рассказа «Метценгерштейн» литературоведы традиционно демонстрируют влияние немецкой литературы на творчество По, так как в сюжет были включены многие элементы, характерные для немецких сказок: мрачный замок, намёки на тайные грехи и семейное проклятие, патологические, пограничные состояния героев, явно ощущаемый средневековый колорит, несмотря на отсутствие в тексте прямых указаний на место и время действия: “These grotesque and arabesque delineations are full of variety, now irresistibly quaint and droll, and again marked with all the deep and painful interest of the German school” [21, p. 42]. / «Эти гротескные и фантастические зарисовки разнообразны, чрезвычайно причудливые и странные, и вновь отмечены совершенно, абсолютно глубоким и болезненным интересом к немецкой школе» (здесь и далее перевод автора статьи. - Л. Ж.). Все эти особенности найдут отражение в последующих новеллах американского писателя. В его текстах мрачный разрушающийся дом часто становится местом действия, затаенная месть и неопределенные внутренние мотивы персонажей выступают катализатором действия, а явное пренебрежение обыденной стороной жизни намекает на внеземное, потустороннее происхождение некоторых героев.

Нет единого мнения, почему По использовал подзаголовок «История в немецком стиле» в данной новелле, если он сам при этом отрицал влияние германизма на свою прозу. Специалисты не согласны с тем, что писатель пытался высмеять или спародировать готические жанры, демонстрируя их ключевые элементы в юмористическом ключе [9; 11; 13].

Определяя роль компонентов немецкой культуры в этой новелле, важно понимать причины обращения По к иным культурам и языкам в принципе. Жанровые эксперименты По, его поиски психологизма относятся именно к периоду создания новеллы «Метценгерштейн». Исследование иноязычных вкраплений в новеллах По позволило прийти к выводу о том, что их модификации сопровождают ключевые изменения в жанровой специфике прозы По, отражают их, становясь своеобразными индикаторами жанровой принадлежности того или иного произведения [3]. Воспроизведение слов иных языков, чужого акцента служило в прозе По средством создания комического эффекта. Первой публикации новеллы «Метценгерштейн» сопутствовал выход еще трех коротких историй («Герцог де Л’Омлет», «На стенах иерусалимских» и «Бон-Бон»), изобилующих включениями из иностранных языков и отличающихся как раз очевидным присутствием в них элементов гротеска и сатиры.

В противовес этому сюжетное отражение некоторых элементов готического произведения и отсутствие значительного числа иноязычных лексических единиц в тексте, как в «Метценгерштейне», могли быть признаками перехода писателя к серьезному жанру психологической новеллы: «Если, скажем, “Герцог де Л’Омлет” и “Без дыхания” - новеллы недвусмысленно ироничные и пародийные, то относительно “Свидания” или “Метценгерштейна” мы не можем быть вполне уверены... По-видимому, правы те критики, которые полагают, что, сочиняя пародии и сатиры, Эдгар По учился писать серьезную прозу, и что в ранних его опытах, какова бы ни была их стилистика, кристаллизовался жанр психологической новеллы» [4, с. 170]. Таким образом, для пародийных новелл характерно явное присутствие иноязычных вкраплений - фактически в тексте обнаруживаются иностранные слова, с развитием же психологизма в новелле эти языковые вкрапления могли исчезать. Эта закономерность подтверждается и публикационной историей новеллы «Свидание» (“Assignation”, 
позже выходила под заголовком “Visionary”). Если ее первая публикация в 1834 г. сопровождалась большим эпиграфом на немецком языке из Шиллера и Гёте, то впоследствии он был заменен цитатой на английском языке, а сама доля пародии в ней ощущалась уже не так явно.

В новеллах «Герцог де Л’Омлет», «Бон-Бон» образы немецкой литературы и философии представлены именно в логике раннего периода развития творчества По - в пародийном, сниженном ключе. Эти тексты объединены инфернальной тематикой, давно известной в литературе (Гёте, Шамиссо, Гофман), в частности, фигурой черта, который в данном случае реализует возмездие для персонажей, воплощающих глупость и самодовольство. В этих новеллах По высмеивает излишнюю ученость немецких мыслителей, их оторванность от реальной жизни. Однако и в более поздних «экстраваганцах» По «Черт на колокольне» (“The Devil in the Belfry”, 1839), «Ангел необъяснимого» (“Angel of the Odd”, 1844) содержатся не только аллюзии на немецкие литературные образы, трансформации которых формируют пародийное поле новелл. В этих коротких рассказах сам немецкий язык выступает инструментом создания комического эффекта, имитируя, например, чужеземный акцент.

Еще одним примером влияния немецкой литературы на творчество По можно назвать заимствование мотива доппельгангера. Сюжет о раздвоении личности, «аномалии» психического сознания человека, неоднократно использовался в прозе американского писателя, наряду с вариациями на тему «духа извращения». В частности, этот мотив стал смыслообразующим в сюжете о страннике Вильяме Вильсоне (“William Wilson”, 1839), повествовании о Метценгерштейне, а также в более поздних психологических новеллах-самообличениях. Некоторые исследователи отмечают влияние рассказа Гофмана «Угловое окно» на новеллу По «Человек толпы» (“The Man of the Crowd”, 1840), а квинтэссенцией сути рассказа можно назвать фразу на немецком языке, прозвучавшую вначале: "It was well said of a certain German book that "er lasst sich nicht lesen" - it does not permit itself to be read” [17, p. 267]. / «Было хорошо сказано об одной немецкой книге: “er lasst sich nicht lesen” она не позволяет себя прочесть».

В истории о Вильяме Вильсоне есть и прямые отсылки к немецкоязычному миру: “...at Rome, with how untimely, yet with how spectral an officiousness, stepped he in between me and my ambition! At Vienna, too, at Berlin, and at Moscow!” [19, p. 211]. / «В Риме, как не вовремя и при этом с какой навязчивостью призрака, он встал между мною и моей целью! В Вене - тоже, как и в Берлине и в Москве!».

В так называемых пейзажных новеллах отмечается полемика американского писателя с немецкой литературой на концептуальном уровне. Так, в коротком рассказе «Поместье Арнгейм» (“The Domain of Arnheim”), впервые опубликованном в 1842 г. под названием “The Landscape Garden”, нашло отражение развенчание некоторых романтических штампов, в частности йенского романтизма. В оригинале использован любимый прием По - нагромождение несопоставимых деталей, которое становится очевидным только при внимательном прочтении и анализе элементов текста [6, с. 94-104]. В данном случае с его помощью вновь конструируется пространство «материальной фантастики», о котором писал Ф. М. Достоевский [2, с. 230]. Таким образом у внимательного читателя формируется идея о том, что естественная красота природы невозможна. Помимо стилистических особенностей повествования, призванных сформировать ощущение фантастичности описываемого в новелле пространства и привести читателя к мысли о недостижимости идеала, сам автор приходит к антиромантическому заключению: «...в природе не существуют сочетания элементов пейзажа, равного тем, что способен сотворить гениальный живописец» [7].

\section{Восприятие творчества Э. А. По в Германии}

Восприятие творчества По в Германии получило противоречивые оценки. Х. Брэдди в 1953 г. писал, что «тевтонское» восхваление По, за исключением литературной критики, значительно запоздало по сравнению с остальными европейскими странами. Другие исследования формируют иной образ. Так, Х. Х. Кунельт называл По самым читаемым и обсуждаемым американским автором в Германии, в то время как К. Любберс утверждал, что По всегда был более признан немцами, нежели американцами. Примером чрезвычайной популярности По в Германии можно считать тот факт, что это единственный американский автор, включенный в коллекцию мировой классики, опубликованной в 1980 г. для широкой публики в Германии [12, р. 39]. У По была хорошая репутация в Германии и других немецкоязычных странах как у поэта, писателя и теоретика, привлекавшего внимание и читателей, и исследователей литературы.

До недавнего времени самым ранним переводом из По на немецкий язык считались переводы рассказов «Колодец и маятник», «Три воскресенья на одной неделе» и стихотворения «Ворон», опубликованные в 1853 г. В 1993 г. был обнаружен перевод новеллы «Низвержение в Мальстрем» (“A Descent into the Maelström”), относящийся к 1846 г. Таким образом, можно сказать, что По вошел в немецкую рецепцию почто в то же время, что и во Франции.

Что касается критической рецепции, то в 1849 г. об Э. По писали в публикации, посвященной иностранной литературе, а четыре года спустя автор анонимной статьи в ведущем немецком журнале провозгласил, что его имя навсегда войдет в анналы американской литературы. В середине XIX в. около десяти изданий избранных работ По были опубликованы на немецком языке. До XX в., за исключением Ф. Шпильгагена, признание По как создателя коротких историй ограничивалось авторами в основном детективных историй. K началу XX в. его популярность превосходила славу Ф. Купера и других известных американских авторов [Ibidem, p. 41]. 
В начале XX в., как и в России, в Германии интерес к творчеству По главным образом стимулировался уже сформированным к тому времени культом личности писателя, что соответствовало биографическому подходу в исследованиях литературы того периода. С подачи Ш. Бодлера По считали романтической фигурой, в нем видели жертву материалистического мира. Историческая перспектива в конце концов сменилась психоаналитическим подходом, который внедрил фокус на медицинские и психологические аспекты работ По. Психоаналитическая интерпретация творчества американского автора, написанная М. Бонапарт и которой при издании предшествовало предисловие Фрейда, с большим успехом была принята в Германии.

Вектор рецептивного усвоения творчества По в Германии был направлен от его поэзии к детективным новеллам и позже к так называемым страшным, готическим новеллам. Однако очевидно воздействие американского писателя на более поздних немецких авторов. Он косвенно, через Бодлера, повлиял на Р. М. Рильке. К. Х. Штробль и Х. Х. Эверс стали родоначальниками современного культа По в Германии и Австрии, обнаружив первыми символическую сущность его прозы и сделав акцент на визионерском мистицизме его новелл. А. Кубин и Г. Майринк инкорпорировали элементы прозы По в собственные произведения. Некоторые исследователи отмечают родство фантастических ситуаций у Э. По и Ф. Кафки.

Проза По обладает явным интермедиальным потенциалом, доказательство чему - многочисленные экранизации, постановки и даже оперы, созданные по мотивам его произведений. В аспекте изучения восприятия творчества По в Германии интересным представляется творческое усвоение новеллы «Вильям Вильсон», которая была воплощена в нескольких экранизациях. Впервые это было сделано в 1913 г.: в Германии на экраны вышел немой фильм «Пражский студент» (“Der Student von Prag”, реж. Стеллан Рийе), который являлся, по мнению некоторых исследователей, первым полноценным фильмом ужасов [5, с. 105]. Примечательно, что изменения в сюжете, в частности, модификация места действия, вновь порождают аллюзии на немецкую литературу. Данная экранизация, чей сценарий был написан Х. Х. Эверсом, представляет собой некий микс из американского и немецкого сюжета, переложенный в иную знаковую систему. Идея о раздвоении личности, двойственности человеческой натуры и личностной трансформации, положенная в основу американской новеллы, нашла прямой отклик в немецком кинематографе и в дальнейшем. Картина была переснята в Германии в 1926 г. под началом режиссера Х. Галина. Третья немецкая экранизация, имевшая такое же название, “Der Student von Prag”, вышла в 1935 г., после прихода в кинематограф звука (режиссёр А. Робинсон). Новеллы «Вильям Вильсон» и «Метценгерштейн», обладающие потенциалом «германизма», в 1968 г. вошли в киноальманах «Три шага в бреду» (“Histoires extraordinaires”) франко-итальянского производства, под руководством режиссера Луи Маля [14].

\section{Заключение}

Проведенное исследование позволило прийти к следующим выводам.

В прозе По выделяются определенные сюжетные константы, имевшие начало в немецкой готической литературе и способствовавшие формированию серьезных жанров в творчестве писателя: элементы хронотопа, характерные для готического повествования, мотив доппельгангера, включение в фабулу инфернальных персонажей в качестве действующих лиц. Свидетельством творческого диалога писателя с немецкой культурой являются также признаки его полемики с немецким романтизмом и попытки развенчания романтических штампов в пейзажных новеллах.

При этом немецкий язык представлен в новеллах По вкраплениями, которые в совокупности придают прозе пародийную, сатирическую окраску, в отличие от сюжетных элементов готики. В целом немецкий язык непосредственно служил средством создания комического эффекта в отдельных новеллах писателя.

Характер влияния немецкого мира на прозу По нашел отражение в картине рецепции его творчества в Германии. Психологизм прозы По, во многом проявившийся под влиянием готической немецкой литературы, стал благоприятной основой для формирования интереса писателей и критиков Германии к творчеству американского писателя. Особенности рецепции прозы По и ее воздействия на немецких авторов можно объяснить как раз наличием близкого им начала, присутствующего в американских оригиналах. Интермедиальный потенциал новелл способствовал их творческой интерпретации в киноиндустрии и музыкальной культуре.

Перспективы дальнейшего исследования заключаются в развитии двух направлений. Исследовательский интерес представляет немецкая интерпретация традиционных готических мотивов, трансформированных По. Актуальным видится и изучение немецких переводов новелл По на предмет воспроизведения в них как элементов готического, так и вкраплений из немецкого языка.

\section{Список источников}

1. Абсалямова Э. Н. Языки необъяснимого: страх, смех и творчество // По, Бодлер, Достоевский: блеск и нищета национального гения: коллективная монография. М.: НЛО, 2017. С. 189-215.

2. Достоевский Ф. М. Три рассказа Эдгара По // Время. 1861. № 1. Отд. І. С. 230-231.

3. Жулёва Л. П. Иноязычные вкрапления в прозе Э. А. По и их русская переводческая рецепция // Вестник Томского государственного университета. Филология. 2018. № 53. С. 179-192. 
4. Ковалев Ю. В. Эдгар Аллан По. Новеллист и поэт. Л.: Художественная литература, 1984. 296 с.

5. Маркулан Я. К. Киномелодрама. Фильм ужасов: кино и буржуазная массовая культура. Л.: Искусство, 1978. 191 с.

6. Осипова Э. Ф. Загадки Эдгара По: исследования и комментарии. СПб.: Филологический факультет СПбГу, 2004. $170 \mathrm{c}$.

7. По Э. А. Поместье Арнгейм [Электронный ресурc]. URL: http://www.lib.ru/INOFANT/POE/arngejm.txt (дата обращения: 18.02.2021).

8. Танасейчук А. Б. Эдгар По. Сумрачный гений. М.: Молодая гвардия, 2015. 436 с.

9. Bittner W. Poe: A Biography. Boston: Little, Brown and Company, 1962. 306 p.

10. Collmer Th. Poe oder der Horror der Sprache. Augsburg: Maro, 1999. $400 \mathrm{~S}$.

11. Fisher B. F. Poe’s “Metzengerstein”: Not a Hoax // On Poe: The Best from American Literature / ed. by E. H. Cady, L. J. Budd. Durham: Duke University Press, 1993. P. 142-149.

12. Forclaz R. Poe in Germany and Austria // Poe abroad: Influence, reputation, affinities / ed. by L. D. Vines. Iowa City: University of Iowa Press, 1999. P. 38-44.

13. Meyers J. Edgar Allan Poe: His Life and Legacy. N. Y.: Cooper Square Press, 1992. 64 p.

14. Nineteenth-Century American Fiction on Screen / ed. by R. B. Palmer. Cambridge: Cambridge University Press, 2007. 262 p.

15. Peeples S. The Afterlife of E. A. Poe. Rochester: Camden House, 2004. 199 p.

16. Poe E. A. Metzengerstein // Southern Literary Messenger. 1836. Vol. II. № 2. P. 97-100.

17. Poe E. A. The Man of the Crowd // Burton’s Gentleman’s Magazine. 1840. Vol. VII. № 6. P. 267-270.

18. Poe E. A. The Philosophy of Composition// The Works of Edgar Allan Poe / ed. John H. Ingram. 1875. Vol. III. P. $266-278$.

19. Poe E. A. William Wilson // Burton’s Gentleman’s Magazine. 1839. Vol. V. №. 4. P. 205-212.

20. Smith D. G. The Poe Cinema: A Critical Filmography of Theatrical Releases Based on the Works of E. A. Poe. Jefferson: McFarland \& Co., 1999. 307 p.

21. Thomas D., Jackson D. K. The Poe Log: A Documentary Life of Edgar Allan Poe, 1809-1849. Boston: G. K. Hall \& Co., 1987. $279 \mathrm{p}$.

22. Vines L. D. Poe abroad: Influence, reputation, affinities. Iowa City: University of Iowa Press, 1999. 284 p.

23. Weissberg L. E. A. Poe. Stuttgart: J. B. Metzler, 1991. 252 S.

\section{Информация об авторах | Author information}

RU Жулёва Лидия Петровна ${ }^{1}$, к. филол. н.

${ }^{1}$ Национальный исследовательский Томский государственный университет

EN Zhuliova Lidia Petrovna ${ }^{1}, \mathrm{PhD}$

${ }^{1}$ National Research Tomsk State University

${ }^{1}$ lidiadmitrieva2205@gmail.com

\section{Информация о статье | About this article}

Дата поступления рукописи (received): 24.02.2021; опубликовано (published): 30.04.2021.

Ключевые слова (keywords): Э. А. По; новеллы; Германия; готика; перевод; Е. А. Poe; short stories; Germany; Gothic; translation. 